\title{
HOXB13 overexpression is an independent predictor of early PSA recurrence in prostate cancer treated by radical prostatectomy
}

\author{
Cristina Villares Zabalza ${ }^{1}$, Meike Adam ${ }^{2}$, Christoph Burdelski ${ }^{3}$, Waldemar Wilczak ${ }^{1}$, \\ Corina Wittmer ${ }^{1}$, Stefan Kraft ${ }^{1}$, Till Krech $^{1}$, Stefan Steurer ${ }^{1}$, Christina Koop ${ }^{1}$, \\ Claudia Hube-Magg ${ }^{1}$, Markus Graefen ${ }^{2}$, Hans Heinzer ${ }^{2}$, Sarah Minner ${ }^{1}$, Ronald \\ Simon $^{1}$, Guido Sauter ${ }^{1}$, Thorsten Schlomm ${ }^{2,4}$, Maria Christina Tsourlakis ${ }^{1}$ \\ ${ }^{1}$ Institute of Pathology, University Medical Center Hamburg-Eppendorf, Germany \\ ${ }^{2}$ Martini-Clinic, Prostate Cancer Center, University Medical Center Hamburg-Eppendorf, Germany \\ ${ }^{3}$ General, Visceral and Thoracic Surgery Department and Clinic, University Medical Center Hamburg-Eppendorf, Germany \\ ${ }^{4}$ Department of Urology, Section for Translational Prostate Cancer Research, University Medical Center Hamburg-Eppendorf, \\ Germany
}

Correspondence to:

Ronald Simon, e-mail: r.simon@uke.de

Keywords: HOXB13, ERG, PTEN, TMA, prostate cancer

Received: January 16, $2015 \quad$ Accepted: February 24, $2015 \quad$ Published: March 23, 2015

\section{ABSTRACT}

HOXB13 is a prostate cancer susceptibility gene which shows a cancer predisposing (G84E) mutation in $0.1-0.6 \%$ of males. We analyzed the prognostic impact of HOXB13 expression by immunohistochemistry on a tissue microarray containing more than 12,400 prostate cancers. Results were compared to tumor phenotype, biochemical recurrence, androgen receptor (AR) and prostate specific antigen (PSA) as well as molecular subtypes defined by ERG status and genomic deletions of 3p, 5q, 6q, and PTEN. HOXB13 immunostaining was detectable in $51.7 \%$ of 10,216 interpretable cancers and considered strong in $9.6 \%$, moderate in $19.7 \%$ and weak in $22.3 \%$ of cases. HOXB13 expression was linked to advanced pT stage, high Gleason grade, positive lymph node status ( $p<0.0001$ each), high pre-operative PSA levels ( $p=0.01)$, TMPRSS2:ERG fusion, PTEN deletions, AR expression, cell proliferation, reduced PSA expression and early PSA recurrence $(p<0.0001$ each $)$. The prognostic value of HOXB13 was independent from established parameters including Gleason, stage, nodal stage and PSA. Co-expression analysis identified a subset of tumors with high HOXB13 and AR but low PSA expression that had a particularly poor prognosis. HOXB13 appears to be a promising candidate for clinical routine tests either alone or in combination with other markers, including AR and PSA.

\section{INTRODUCTION}

Prostate cancer is the most prevalent cancer in men in Western societies [1]. Although most prostate cancers have a rather indolent clinical course, prostate cancer represents the third most common cause of cancer related death in men. Despite recent advances in molecular research, the only established pretreatment prognostic parameters include Gleason grade and tumor extent on biopsies, preoperative prostate-specific antigen (PSA), and clinical stage. Because these data are statistically powerful but not sufficient for optimal individual treatment decisions, it can be hoped that a better understanding of disease biology will eventually lead to the identification of clinically applicable molecular markers that enable a more reliable prediction of prostate cancer aggressiveness.

The homeobox (HOX) is a specific and widely distributed DNA sequence characterizing genes that are responsive to HOX transcription factors [2]. HOX transcription factors are highly conserved major regulators of developmental processes in many organ systems. Homeobox B13 (HOXB13) is one of the numerous DNAbinding transcription factors of the HOX gene family that has been implicated in the development of normal prostate and cancer [3]. In the normal prostate gland, HOXB13 forms complexes with the androgen receptor (AR) and acts 
as an important modulator of the transcriptional activity of both androgen independent and androgen responsive genes [4]. Depending on the presence or absence of other transcription factors these complexes can stimulate transcription of certain target genes and suppress others such as prostate specific antigen (PSA) [4]. Recent data have established HOXB13 as a strong candidate gene for causing hereditary prostate cancer if mutated. A rare HOXB13 polymorphism (G84E) occurring in $0.1-0.6 \%$ of European/American populations has been linked to an increased prostate cancer risk by several groups [5-10]. Men with G84E mutations have a 3-5 fold higher risk for developing prostate cancer and develop their tumors earlier than patients without this deletion $[6,11]$. Several studies have further used immunohistochemistry to show that HOXB13 is often expressed at high levels in prostate cancer [12-15].

Given the potential importance of HOXB13 for prostate cancer development, we wondered whether HOXB13 expression levels would be linked to disease outcome or relevant clinical or molecular subgroups. For this purpose, we took advantage of our preexisting tissue microarray containing more than 12,400 prostate cancer specimens with clinical follow-up and attached molecular database. The results of our study demonstrate that high levels of HOXB13 is tightly linked to unfavorable patient outcome.

\section{RESULTS}

\section{Technical issues}

A total of 10,216 (91.6\%) of tumor samples were interpretable in our TMA analysis. Reason for noninformative cases (935 spots; 8.4\%) included lack of tissue samples or absence of unequivocal cancer tissue in the TMA spot.

\section{HOXB13 immunohistochemistry}

Normal prostatic glands showed weak nuclear staining. Positive staining was limited to the secretory epithelial cells, while basal cells were consistently negative. In cancers, HOXB13 staining was seen in 5,278 of our 10,216 (51.7\%) interpretable tumors and was considered weak in $22.3 \%$, moderate in $19.7 \%$ and strong in $9.6 \%$ of cancers (Table 1). Representative images of HOXB13 immunostainings are given in Figure 1A-1D.

\section{Association with TMPRSS2:ERG fusion status and ERG protein expression}

To evaluate whether HOXB13 expression is associated with ERG status in prostate cancers, we used data from previous studies (expanded from [18, 19]). Data on TMPRSS2:ERG fusion status obtained by FISH were available from 5,677 and by immunohistochemistry from
8,459 tumors with evaluable HOXB13 immunostaining. Data on both ERG FISH and IHC were available from 5,468 cancers, and an identical result (ERG IHC positive and break by FISH or ERG IHC negative and missing break by FISH) was found in 5,231 of 5,468 (95.7\%) cancers. HOXB13 immunostaining was strongly linked to presence of TMPRSS2:ERG rearrangements and ERG expression. HOXB13 expression was seen in $63.4 \%$ (ERG IHC) and $64.1 \%$ (ERG FISH) of ERG-positive cancers but in only $44.1 \%$ and $49.9 \%$ of cancers without ERG staining and ERG rearrangement, respectively $(p<0.0001$ each; Figure 2). HOXB13 immunostaining was linked to advanced pathological tumor stage, high Gleason grade, and lymph node metastasis ( $p<0.0001$ each) in subsets of both ERG-negative (Supplementary Table 2) and ERGpositive cancers (Supplementary Table 3).

\section{Association to key genomic deletions}

Earlier studies had provided evidence for recurrent chromosomal deletions delineating further molecular subgroups amongst ERG positive and ERG negative prostate cancers. In particular, deletions of PTEN and 3 p13 define subgroups in ERG positive and deletions of 5 q21 and 6q15 define subgroups in ERG negative cancers $[20,21,23]$. To examine, whether HOXB13 expression might be particularly associated with one of these genomic deletions, HOXB13 data were compared to preexisting findings on PTEN (10q23), 3p13 (FOXP1), 6q15 $(M A P 3 K 7)$ and 5q21(CHD1) deletions. Elevated HOXB13 expression levels were strongly linked to deletions of PTEN in all cancers (Figure 3A) as well as in the subsets of ERG- negative (Figure 3B) and ERG- positive cancers $(p<0.0001$ each, Figure 3C). However, HOXB13 was largely unrelated to all other deletions irrespective of whether all cancers or subgroups of ERG positive or ERG negative cancers were analyzed.

\section{Associations between immunohistochemical expression of HOXB13, AR and PSA}

To search for associations between expression of HOXB13 and its co-regulator AR, we included data from a previous study [19]. There was a strong positive link between overexpression of HOXB13 and high-level AR expression ( $p<0.0001$, Figure 4A). Strong HOXB13 expression was found in $17 \%$ of cancers with strong $A R$ expression, but only in $1.3 \%$ of AR-negative tumors. HOXB13 and AR expression were further compared to PSA immunohistochemical results because PSA was described to be down regulated by AR/HOXB13 [25]. As expected from these studies, HOXB13 was inversely linked to PSA ( $p<0.0001$, Figure 4B). Strong PSA expression was seen in $55.1 \%$ of HOXB13-negative tumors, but only in $33.1 \%$ of cancers with strong HOXB13 expression. Likewise, AR expression was inversely related to PSA levels. High-level PSA was found in $65.9 \%$ of 
Table 1: Association between HOXB13 immunostaining results and prostate cancer phenotype

\begin{tabular}{|c|c|c|c|c|c|c|}
\hline & \multirow[t]{2}{*}{$n$ evaluable } & \multicolumn{4}{|c|}{ HOXB13 IHC result (\%) } & \multirow[t]{2}{*}{$P$ value } \\
\hline & & negative & weak & moderate & strong & \\
\hline All cancers & 10,216 & 48.3 & 22.3 & 19.7 & 9.6 & \\
\hline \multicolumn{7}{|l|}{ Tumor stage } \\
\hline pT2 & 6,691 & 52.1 & 22.6 & 17.8 & 7.4 & $<0.0001$ \\
\hline pT3a & 2,241 & 43.1 & 21.7 & 22.5 & 12.8 & \\
\hline pT3b & 1,177 & 36.8 & 22.3 & 24.8 & 16.1 & \\
\hline pT4 & 62 & 37.1 & 14.5 & 33.9 & 14.5 & \\
\hline \multicolumn{7}{|c|}{ Gleason grade } \\
\hline$\leq 3+3$ & 2,577 & 60.3 & 20.1 & 15.0 & 4.6 & $<0.0001$ \\
\hline $3+4$ & 5,693 & 46.3 & 23.6 & 20.4 & 9.7 & \\
\hline $4+3$ & 1,448 & 37.7 & 21.6 & 25.1 & 15.5 & \\
\hline$\geq 4+4$ & 442 & 37.6 & 21.5 & 22.2 & 18.8 & \\
\hline \multicolumn{7}{|c|}{ Lymph node metastasis } \\
\hline N0 & 5,657 & 46.2 & 22.6 & 20.1 & 11.1 & $<0.0001$ \\
\hline $\mathrm{N}+$ & 528 & 34.7 & 20.9 & 24.6 & 19.9 & \\
\hline \multicolumn{7}{|c|}{ Preop. PSA level (ng/ml) } \\
\hline$<4$ & 1,267 & 46.3 & 22.6 & 22.1 & 9.0 & 0.01 \\
\hline $4-10$ & 6,137 & 48.0 & 23.3 & 19.3 & 9.4 & \\
\hline$>10-20$ & 2,006 & 48.7 & 21.0 & 19.7 & 10.5 & \\
\hline$>20$ & 686 & 52.2 & 17.8 & 10.5 & 10.6 & \\
\hline \multicolumn{7}{|c|}{ Surgical margin } \\
\hline negative & 8,212 & 48.7 & 22.8 & 19.2 & 9.4 & 0.0004 \\
\hline positive & 1,824 & 46.6 & 20.1 & 22.5 & 10.9 & \\
\hline
\end{tabular}

AR-negative cancers, but only in $39 \%$ of strongly ARpositive tumors $(p<0.0001$, Figure $4 C)$.

\section{Association to tumor cell proliferation (Ki67LI)}

Strong HOXB13 staining was significantly linked to accelerated cell proliferation as measured by Ki67LI in all cancers $(p<0.0001)$. This association held also true with high significance in most subgroups of cancers with comparable Gleason grade $(\leq 3+3 ; 3+4 ; 4+3 ; \geq 4+4$, Table 2).

\section{Association with PSA recurrence}

Follow-up data were available from 9,474 patients with interpretable HOXB13 immunostaining on the TMA. Increasing levels of HOXB13 were equally paralleled by decreasing PSA recurrence-free intervals if all cancers were jointly analyzed ( $p<0.0001$, Figure $5 \mathrm{~A})$, as in subsets of ERG-IHC-positive $(p<0.0001$, Figure 5B) or ERG-IHC-negative cancers $p<0.0001$, Figure 5C). Because of the strong associations between HOXB13, AR and PSA, we extended the analyses to tumor subgroups stratified according to the following criteria 1) cancers with strong PSA staining irrespective of the HOXB13 and AR results (group 1: PSA high), 2) cancers with low (negative to weak) HOXB13 expression or low (negative to moderate) AR expression but low (negativemoderate) PSA expression (group 2: HOXB13 or AR low), and cancers with high (moderate-strong) HOXB13 expression and high (strong) AR expression but low PSA expression (group 3: HOXB13 and AR high, PSA low). These analyses revealed marked prognostic differences: Tumors with high PSA had the best, and tumors with high HOXB13 and AR, but low PSA, had the worst prognosis, while an intermediate prognosis was found for tumors with low expression of at least one of HOXB13 or AR $(p<0.0001$, Figure 5D). These differences held also true in subsets of ERG-positive ( $p<0.0001$, Figure 5E) and ERG-negative cancers $(p<0.0001$, Figure 5F). 

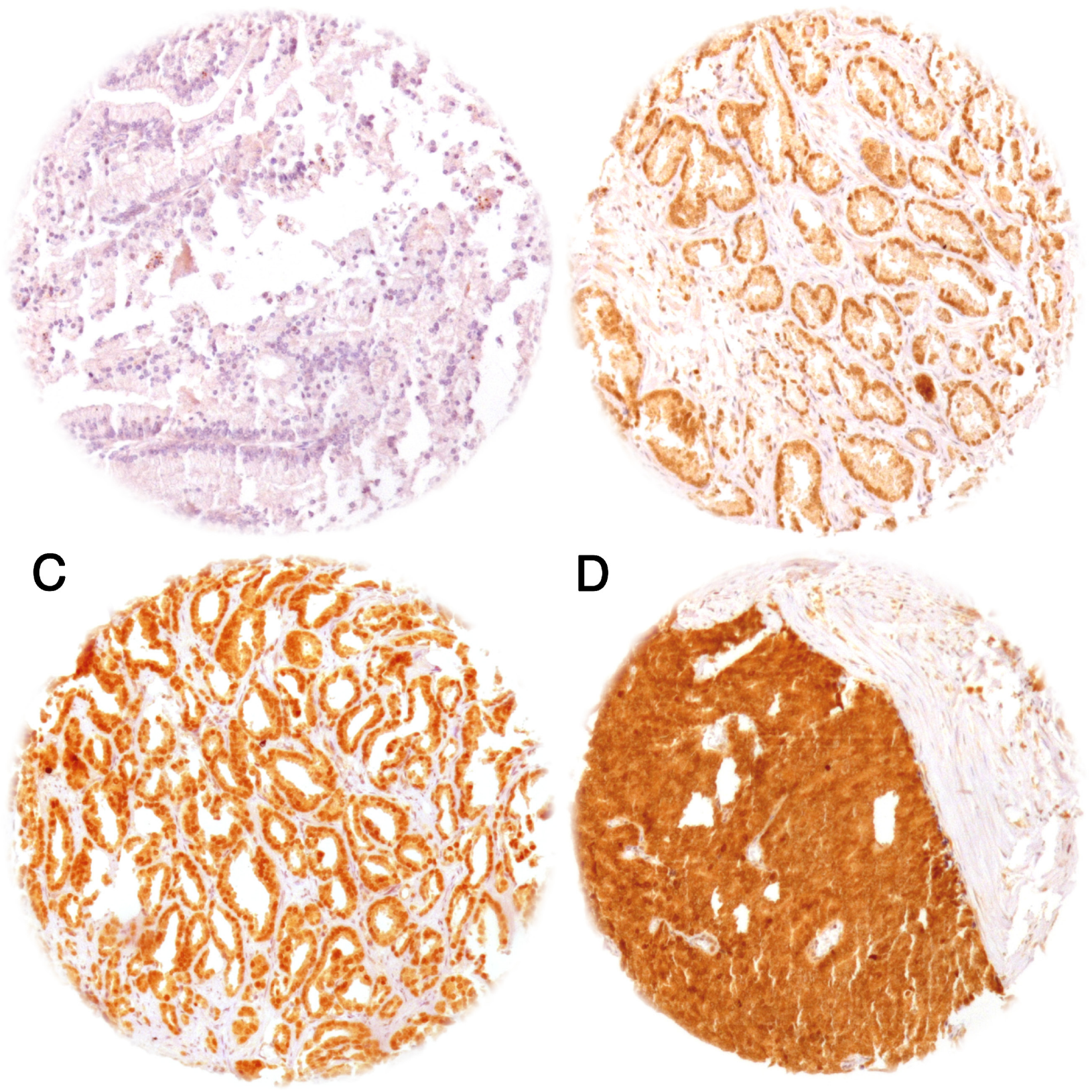

Figure 1: Representative pictures of HOXB13 immunostaining in prostate cancer. (A) negative (no nuclear staining), (B) weak, (C) moderate, and (D) strong staining.

\section{Multivariate analysis}

Four different types of multivariate analyses were performed evaluating the clinical relevance of HOXB13 expression in different scenarios (Table 3). Scenario 1 evaluated all postoperatively available parameters including pathological tumor stage, pathological lymph node status $(\mathrm{pN})$, surgical margin status, preoperative PSA value and pathological Gleason grade obtained after the morphological evaluation of the entire resected prostate. In scenario 2, all postoperatively available parameters with exception of nodal status were included. The rational for this approach was that the indication and extent of lymph node dissection is not standardized in the surgical therapy of prostate cancer and that excluding $\mathrm{pN}$ in multivariate analysis can markedly increase case numbers. Two additional scenarios had the purpose to model the preoperative situation as much as possible. Scenario 3 included HOXB13 expression, preoperative PSA, clinical tumor stage (cT stage) and Gleason grade obtained on the prostatectomy specimen. Since postoperative determination of a tumors Gleason grade is "better" than 


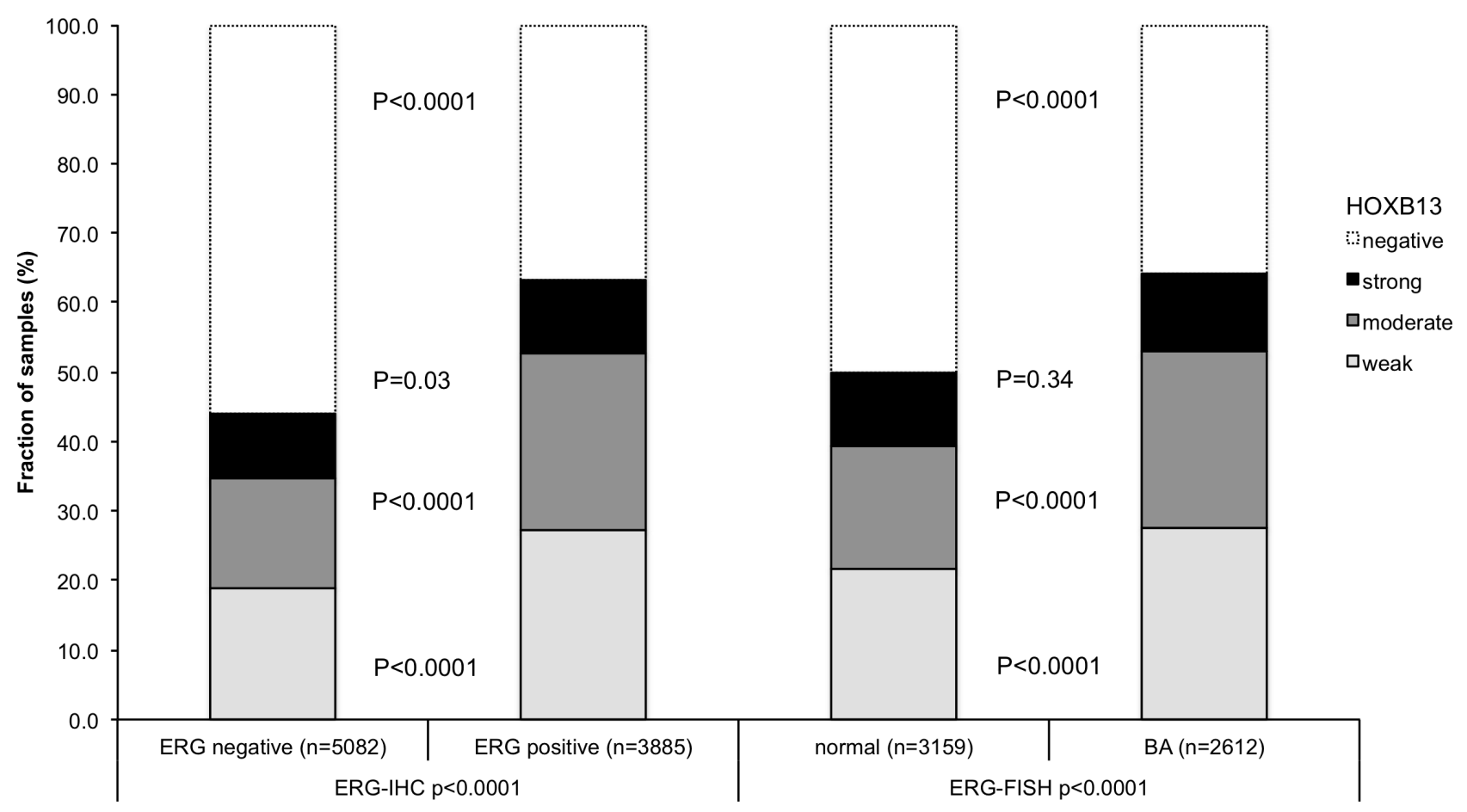

Figure 2: Association between HOXB13 immunostaining results and the ERG-status determined by IHC and FISH analysis. BA (break apart) indicates rearrangement of the ERG gene according to FISH analysis.

the preoperatively determined Gleason grade (subjected to sampling errors and consequently under-grading in more than one third of cases [26]), another multivariate analysis was added. In scenario 4, the preoperative Gleason grade obtained on the original biopsy was combined with preoperative PSA, cT stage and HOXB13 expression. These analyses revealed that HOXB13 expression levels provided independent prognostic information in almost all scenarios.

\section{DISCUSSION}

The results of our study identify HOXB13 overexpression as a strong prognostic factor in prostate cancer, and suggest clinically relevant in-vivo interactions with its binding partner androgen receptor.

The immunohistochemistry protocol was designed to detect expression differences between individual prostate cancers in this study. At the selected conditions, our analysis of 10,216 patients revealed no staining in $48.3 \%$ of tumors while $22.3 \%$ had a weak and $29.3 \%$ a moderate to strong HOXB13 immunostaining. These findings indeed suggest a substantial variability of HOXB13 expression in prostate cancer. Data from two other studies using a more sensitive IHC protocol had earlier demonstrated that at least some HOXB13 expression can occur in every prostate cancer. Varinot et al. described strong HOXB13 immunostaining in all 400 analyzed prostate cancers and in secretory cells from all analyzed 120 normal prostates [13], while in another study, moderate to strong HOXB13 expression was found in only $30 \%$ of 44 prostate cancers [12]. These discrepant findings on the HOXB13 positivity rate further illustrate the paramount impact of protocols on IHC data. In an earlier study, we described IHC protocol induced variability of p53 positivity between $<5$ and $>95 \%$ [27]. The significant associations of HOXB13 staining levels with various clinical, pathological and molecular tumor parameters indicate, that our measurements reflect true and biologically relevant expression differences between cancers. The data also demonstrate, that prostate cancers generally show increased HOXB13 expression levels as compared to normal prostate epithelium. This latter observation is in line with a role of HOXB13 overexpression during malignant transformation of prostate epithelial cells.

The data from this study further corroborate recently suggested interactions between HOXB13, AR, and PSA. Work by several groups has indicated, that HOXB13 and androgen receptor complex with each other, and that these complexes jointly regulate the expression of androgen dependent genes [4, 25, 28]. The strong positive correlation of the expression levels of HOXB13 and AR as measured on our TMA is consistent with these assumptions derived from xenograft and cell line experiments [28]. The strong inverse association of HOXB13 and AR expression with PSA staining levels of our tumors represents a strong in vivo validation for down regulation of PSA by AR/HOXB13 that was earlier assumed from cell line experiments [4]. That 


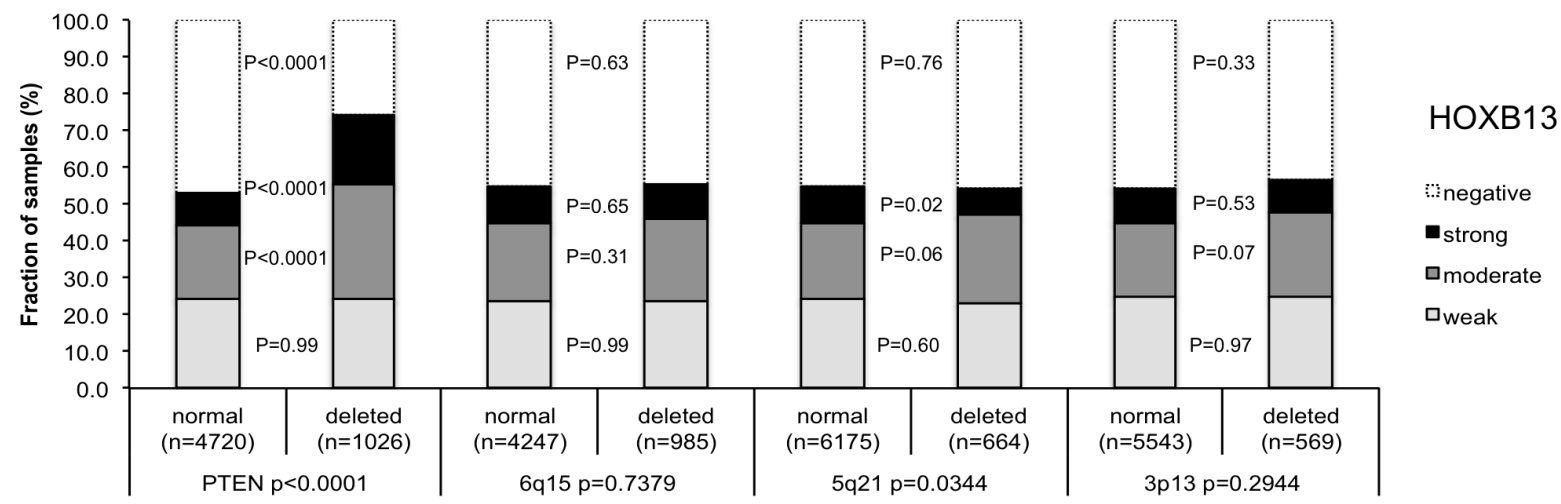

B ERG-negative subset

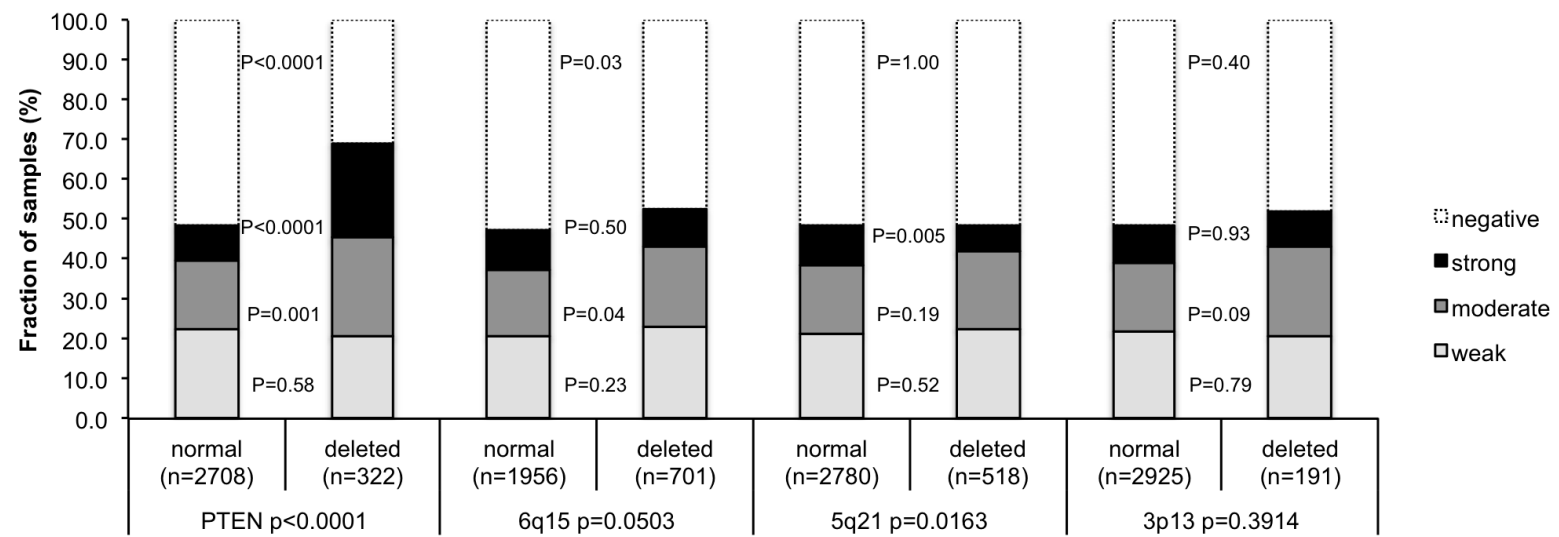

C ERG-positive subset

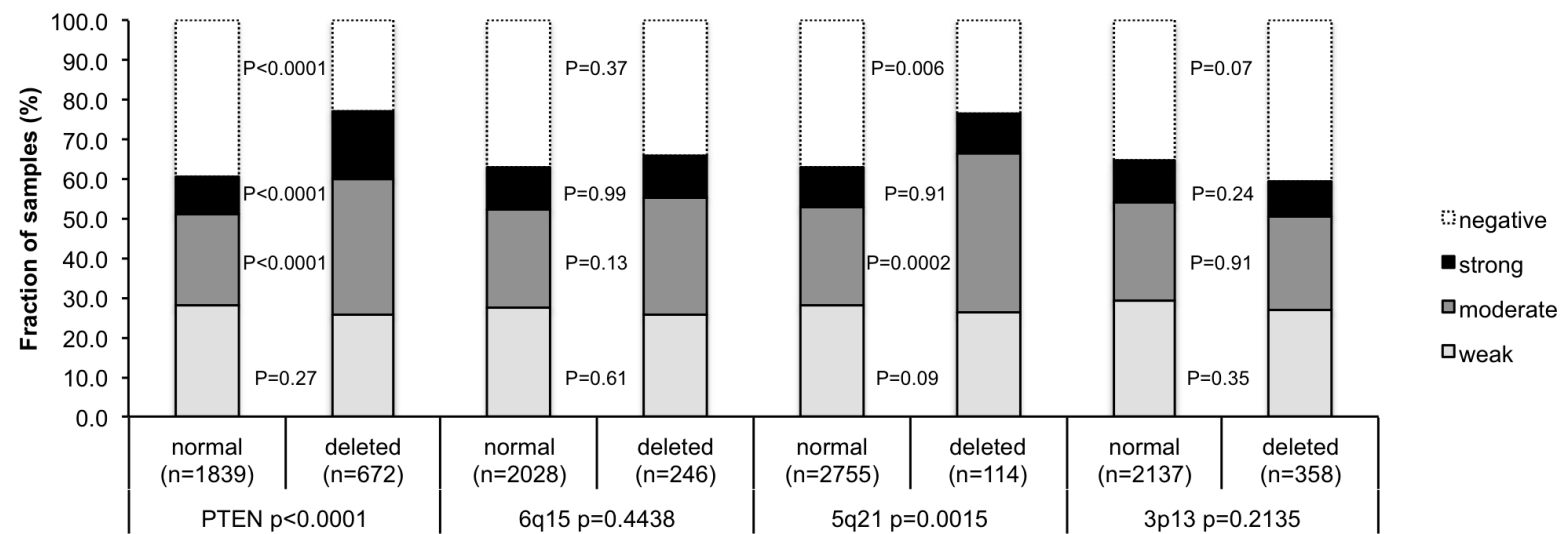

Figure 3: Association between positive HOXB13 immunostaining results and deletions of PTEN, 5q21 (CHD1), 6q15 (MAP3K7), and 3p13 (FOXP1). (A) all cancers, (B) ERG-negative and (C) ERG-positive subset according to ERG-IHC analysis. 

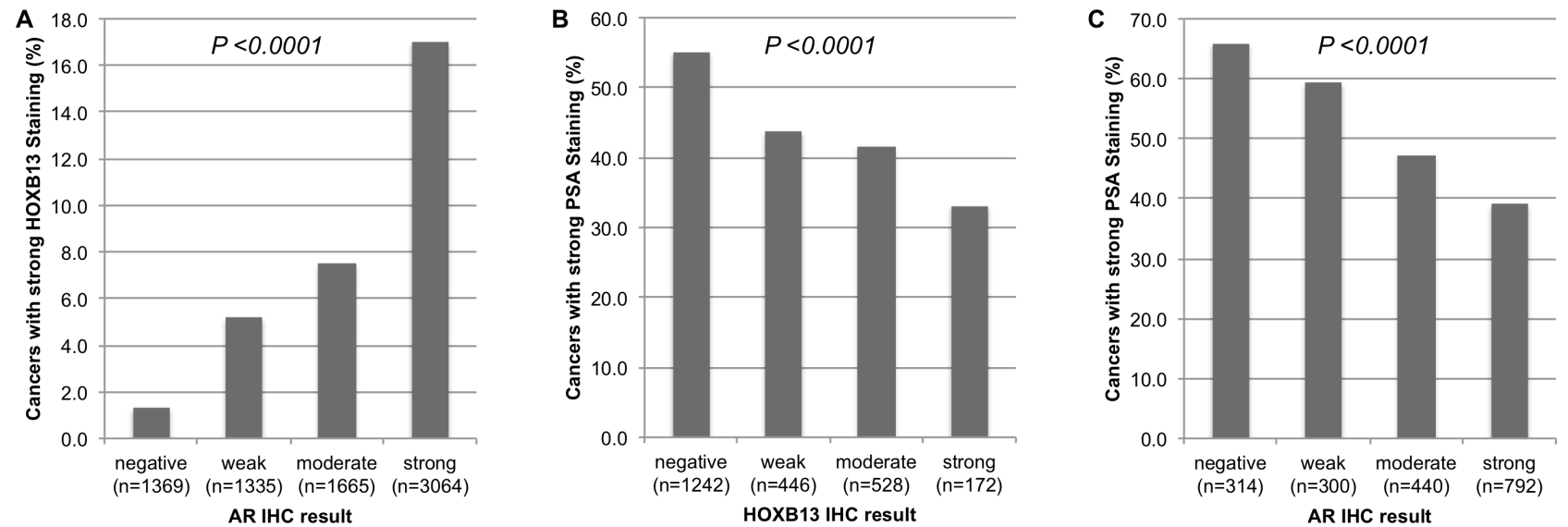

Figure 4: Correlation of IHC parameters HOXB13, androgen receptor (AR) and cytoplasmic PSA. (A) strong HOXB13 expression and AR, (B) strong PSA expression and HOXB13, and (C) strong PSA expression and AR.

Table 2: Associations between HOX13B immunohistochemistry results and cell proliferation as measured by Ki67 immunohistochemistry in all cancers and subsets of cancers defined by Gleason grade

\begin{tabular}{|c|c|c|c|c|c|c|}
\hline & & HOXB13 IHC & $n$ & \multicolumn{2}{|c|}{ Ki67LI } & $P$ value \\
\hline \multirow{4}{*}{ All cancers } & & negative & 3,225 & 2.28 & \pm 0.05 & $<0.0001$ \\
\hline & & weak & 1,519 & 3.09 & \pm 0.07 & \\
\hline & & moderate & 1,309 & 3.14 & \pm 0.07 & \\
\hline & & strong & 658 & 3.51 & \pm 0.10 & \\
\hline \multirow{16}{*}{ Gleason } & $\leq 3+3$ & negative & 936 & 1.89 & \pm 0.07 & $<0.0001$ \\
\hline & & weak & 312 & 2.67 & \pm 0.12 & \\
\hline & & moderate & 219 & 2.40 & \pm 0.14 & \\
\hline & & strong & 73 & 2.77 & \pm 0.24 & \\
\hline & $3+4$ & negative & 1,798 & 2.26 & \pm 0.06 & $<0.0001$ \\
\hline & & weak & 944 & 2.89 & \pm 0.08 & \\
\hline & & moderate & 782 & 3.10 & \pm 0.08 & \\
\hline & & strong & 381 & 3.28 & \pm 0.12 & \\
\hline & $4+3$ & negative & 372 & 3.00 & \pm 0.18 & 0.003 \\
\hline & & weak & 197 & 4.04 & \pm 0.25 & \\
\hline & & moderate & 236 & 3.48 & \pm 0.22 & \\
\hline & & strong & 149 & 3.83 & \pm 0.28 & \\
\hline & $\geq 4+4$ & negative & 95 & 3.76 & \pm 0.49 & 0.15 \\
\hline & & weak & 62 & 5.29 & \pm 0.60 & \\
\hline & & moderate & 68 & 4.88 & \pm 0.58 & \\
\hline & & strong & 52 & 5.23 & \pm 0.66 & \\
\hline
\end{tabular}

Abbreviations: Ki67LI = Ki67 labeling index (mean \pm SEM). 

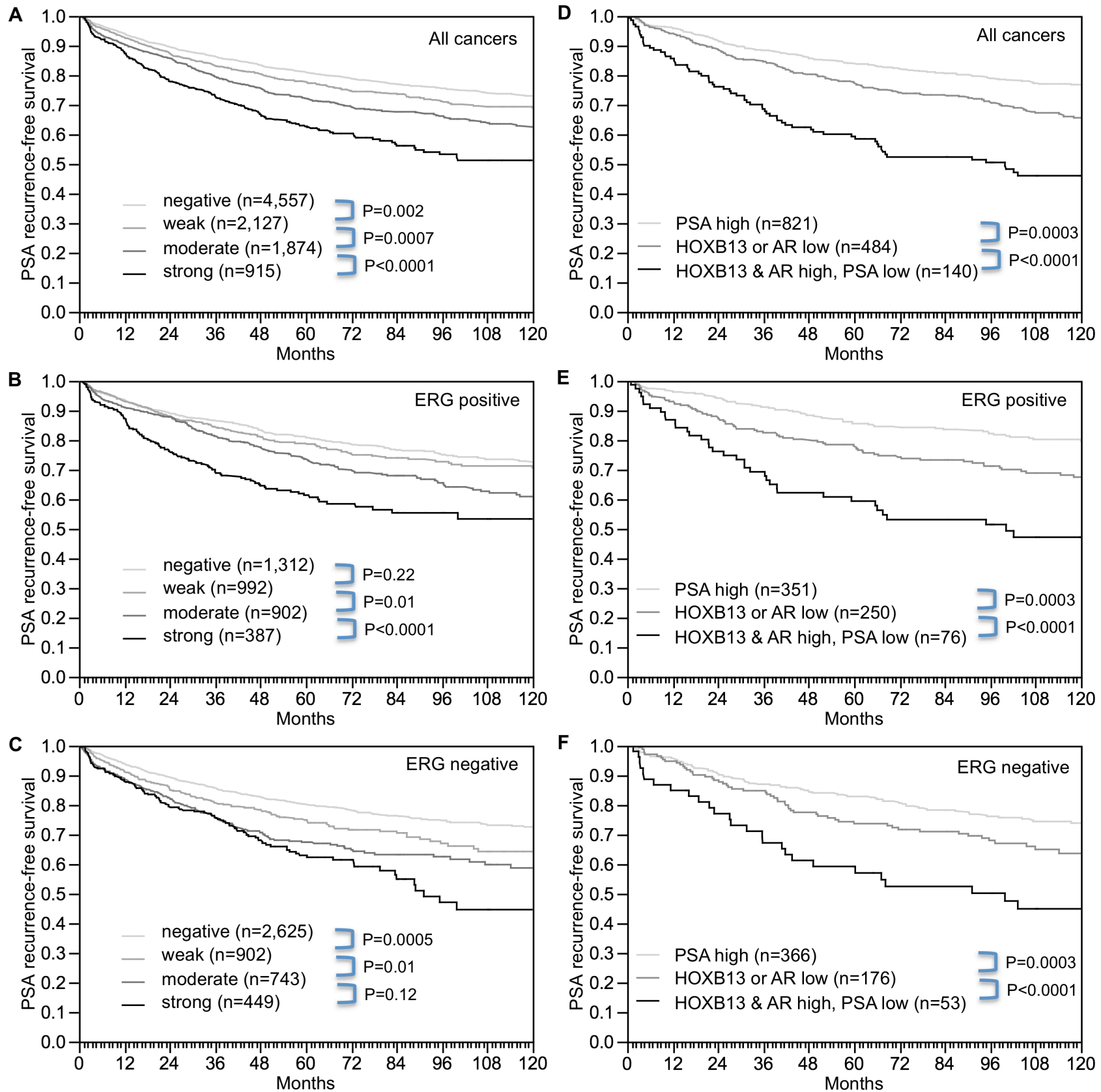

Figure 5: Association between HOXB13 expression and biochemical recurrence. (A) all cancers, (B) ERG-IHC positive cancers, and (C) ERG-IHC negative cancers. Combined effect of HOXB13, AR and PSA in (D) all cancers, (E) ERG-IHC positive cancers, and (F) ERG-IHC negative cancers.

high-level PSA can be found in the majority of ARnegative cancers can be explained by AR-independent up regulation of PSA by the mitogen activated protein (MAP) kinase pathway [29]. Importantly, finding at least some inverse associations of biomarkers always provides strong indirect evidence for the validity of our IHC data. It must be assumed, that a small number $(<10 \%)$ of non-reactive or "under reactive" tissues are regularly included in molecular studies using routinely processed patient material. An unusually high rate of such cases could thus induce a "false" positive association of biomarkers due to concordant negative or "low expression" results for all evaluated biomarkers in a distinct "non-reactive" subgroup of cancers. Inverse associations cannot be caused by a proportion of nonreactive tissues yielding negative IHC results for all analyzed antibodies.

Our notion, that HOXB13 is highly relevant for the biology of prostate cancer is further substantiated by the strong link of high expression with unfavorable tumor phenotype and poor outcome in this study. The high number of cancers included in this analysis 
Table 3: Multivariate analysis including HOXB13 expression in all cancers, the ERG-negative and ERG-positive subset. Scenario 1 includes all postoperatively parameters. Scenario 2 excludes the lymph node $(\mathrm{pN})$ stage. Scenario 3 replaces the pathological tumor $(\mathrm{pT})$ stage with the clinical (cT) stage and omits the surgical margin (R) status. Scenario 4 includes all preoperative available parameters

\begin{tabular}{|c|c|c|c|c|c|c|c|c|c|c|}
\hline \multirow{2}{*}{$\begin{array}{l}\text { Tumor } \\
\text { subset }\end{array}$} & \multirow[t]{2}{*}{ Scenario } & \multirow{2}{*}{$\begin{array}{c}n \\
\text { analyzable }\end{array}$} & \multicolumn{8}{|c|}{$P$ value } \\
\hline & & & $\begin{array}{l}\text { preop. } \\
\text { PSA- } \\
\text { Level }\end{array}$ & pT Stage & cT Stage & $\begin{array}{l}\text { Gleason } \\
\text { grade pros } \\
\text { tatectomy }\end{array}$ & $\begin{array}{c}\text { Gleason } \\
\text { grade } \\
\text { biopsy }\end{array}$ & pN Stage & R-Status & $\begin{array}{c}\text { HOXB13- } \\
\text { Expression }\end{array}$ \\
\hline \multirow{4}{*}{$\begin{array}{l}\text { all } \\
\text { cancers }\end{array}$} & 1 & 5,614 & $<0.0001$ & $<0.0001$ & - & $<0.0001$ & - & $<0.0001$ & $<0.0001$ & 0.005 \\
\hline & 2 & 9,261 & $<0.0001$ & $<0.0001$ & - & $<0.0001$ & - & - & $<0.0001$ & $<0.0001$ \\
\hline & 3 & 9,121 & $<0.0001$ & - & $<0.0001$ & $<0.0001$ & - & - & - & $<0.0001$ \\
\hline & 4 & 8,990 & $<0.0001$ & - & $<0.0001$ & - & $<0.0001$ & - & - & $<0.0001$ \\
\hline \multirow{4}{*}{$\begin{array}{l}\text { ERG- } \\
\text { negative } \\
\text { cancers }\end{array}$} & 1 & 2,871 & $<0.0001$ & $<0.0001$ & - & $<0.0001$ & - & $<0.0001$ & 0.27 & 0.02 \\
\hline & 2 & 4,616 & $<0.0001$ & $<0.0001$ & - & $<0.0001$ & - & - & 0.004 & 0.002 \\
\hline & 3 & 4,577 & $<0.0001$ & - & $<0.0001$ & $<0.0001$ & - & - & - & 0.0002 \\
\hline & 4 & 4,517 & $<0.0001$ & - & $<0.0001$ & - & $<0.0001$ & - & - & $<0.0001$ \\
\hline \multirow{4}{*}{$\begin{array}{l}\text { ERG- } \\
\text { positive } \\
\text { cancers }\end{array}$} & 1 & 2,170 & 0.009 & $<0.0001$ & - & $<0.0001$ & - & 0.17 & 0.0003 & 0.11 \\
\hline & 2 & 3,511 & 0.0002 & $<0.0001$ & - & $<0.0001$ & - & - & $<0.0001$ & 0.06 \\
\hline & 3 & 3,431 & $<0.0001$ & - & $<0.0001$ & $<0.0001$ & - & - & - & 0.006 \\
\hline & 4 & 3,375 & $<0.0001$ & - & $<0.0001$ & - & $<0.0001$ & - & - & 0.0002 \\
\hline
\end{tabular}

further enabled us to study the combined impact of the interrelated biomarkers HOXB13, AR, and PSA. These data suggest a markedly unfavorable prognosis in patients with tumors showing highest evidence for a strong activity of the HOXB13/AR complex including a measurable PSA down-regulation. The strong and independent prognostic impact of this combined feature is in line with the critical role of androgen receptor signaling in prostate cells.

The abundant molecular database attached to our tumor collection further enabled us to analyze the role of HOXB13 in tumors of different molecular subtypes, the most common of which is the TMPRSS2:ERG gene fusion. Gene fusions involving the androgen-regulated gene TMPRSS2 and ERG occur in about $50 \%$ of prostate cancers and result in strong ERG protein overexpression [30] with consequent deregulation of the expression of a large number of genes [31-34]. The strong association of HOXB13 with positive ERG status expression fits well with the known role of androgen receptor activation for development of ERG fusions in prostate cancer [35]. Experimental studies have demonstrated that ERG fusions develop as a result of elevated androgen signaling [36]. About $0.1-0.6 \%$ of men carry a specific HOXB13 germ line mutation (G84E) [5-10, 37]. Interestingly, it was recently shown, that only 5 of 23
$(21.7 \%)$ analyzed prostate cancers from patients with a G84E mutation had an ERG fusion [38] as compared to about $50 \%$ in unselected cohorts [30]. This observation would be consistent with models suggesting that germ line G84E mutations of HOXB13 negatively impact androgen signaling to an extent that ERG fusion development are less likely to occur.

Next to ERG fusions, chromosomal deletions represent the most common recurrent genomic alterations in prostate cancer. Increasing amount of data is suggesting that these deletions may delineate biologically and clinically relevant subgroups within ERG positive and ERG negative cancers as most of these deletions are clearly linked to ERG status. Deletions at 3p13 and 10q23 (PTEN) are associated with ERG-positive cancers, while 5q21 and 6q15 are inked to ERG-negative cancers [22, 39-41]. That several biomarkers considered relevant for prostate cancer cluster with some of these deletions further supports the potential significance of molecular prostate cancer subgroups defined by deletions. For example, CRISP3 overexpression is strongly associated with PTEN deleted ERG positive prostate cancer [42]. SPINK1 expression is tightly linked to 6q15- and 5q21-deleted ERG negative prostate cancers [43]. The data from this study revealed a striking link of strong HOXB13 expression with PTEN deleted ERG positive cancers. Since HOXB13 
is involved in both positive and negative growth control through activation of AKT/mTOR signaling [44] and inhibition of CCND1 [14], it is possible that the association between HOXB13 expression and PTEN deletion reflects compensatory up regulation of HOXB13 in cancer cells with severely deregulated AKT signaling.

Among all cancers, prostate cancer is the one tumor where predictors of the natural course of the disease are most needed. The majority of men develop prostate cancer during their lifetime but only relatively few of them will eventually die of their tumor $[45,46]$. Accidental diagnosis of a low-grade prostate cancer thus poses the problem whether or not this cancer needs therapy. Many individual parameters have been demonstrated as potentially prognostic in earlier studies, but results on most parameters are conflicting [47]. Recent studies have shown promising data for multiparametric prognostic tests in prostate cancer $[48,49]$ and several tests are now commercially available to patients [50-52]. It is most likely, however, that better tests can be developed. For example, several independent prognostic parameters have been identified by our group by using the same large-scale TMA approach as in this study [49, 53-55]. It appears likely, that several of these features as well as other parameters that remain to be detected could add substantially to existing multiparametric tests. Given the strong and independent prognostic role for high HOXB13 expression in all models, we thus hypothesize, that this parameter will be applicable for routine evaluation of prostate cancers - most likely in combination with other relevant features, such as for example AR and PSA expression levels.

In summary, our study highlights HOXB13 as strong and independent prognostic marker in prostate cancer, and a promising candidate for a routine clinical application.

\section{MATERIALS AND METHODS}

\section{Patients}

Radical prostatectomy specimens were available from 11,152 patients, undergoing surgery between 1992 and 2011 at the Department of Urology and the Martini Clinics at the University Medical Center HamburgEppendorf. Follow-up data were available for a total of 7,440 patients with a median follow-up of 36 months (range: 1 to 228 months; Supplementary Table 1). Prostate specific antigen (PSA) values were measured following surgery and PSA recurrence was defined as a postoperative PSA of $0.2 \mathrm{ng} / \mathrm{ml}$ and increasing at first of appearance. All prostate specimens were analyzed according to a standard procedure, including a complete embedding of the entire prostate for histological analysis [16]. The TMA manufacturing process was described earlier in detail [17]. In short, one $0.6 \mathrm{~mm}$ core was taken from a representative tissue block from each patient. The tissues were distributed among 27 TMA blocks, each containing 144 to 522 tumor samples. For internal controls, each TMA block also contained various control tissues, including normal prostate tissue. The molecular database attached to this TMA contained results on ERG expression in 10,711 [18], ERG break apart FISH analysis in 7,122 (expanded from [19]) and deletion status of 5q21 (CHD1) in 7,932 (expanded from [20]), 6q15 (MAP3K7) in 6,069 (expanded from [21]), PTEN (10q23) in 6,704 (expanded from [22]), and 3 p13 (FOXP1) in 7,081 (expanded from [23]), Further immunohistochemical data were available on Ki67LI from 7,010 [24], and on androgen receptor (AR) in 7,856 tumors. (expanded from [24]).

\section{Immunohistochemistry}

Freshly cut TMA sections were immunostained on one day and in one experiment. For HOXB13 immunohistochemistry, slides were deparaffinized and exposed to heat-induced antigen retrieval for 5 minutes in an autoclave at $121^{\circ} \mathrm{C}$ in $\mathrm{pH} 7.8$ Tris-EDTACitrate buffer. Primary antibody specific for HOXB13 (mouse monoclonal antibody, Abcam, Cambridge, UK; cat\# 53931; dilution 1:25) was applied at $37^{\circ} \mathrm{C}$ for 60 minutes. These conditions were selected in order to optimally distinguish between different expression levels of HOXB13. At a dilution of $1: 25$, there were both strongly nuclear positive but also entirely negative prostate cancers. HOXB13 staining was predominantly nuclear and typically paralleled by cytoplasmic costaining. For PSA immunohistochemistry, slides were deparaffinized. No antigen retrieval step was performed. Primary antibody specific for PSA (mouse monoclonal antibody, Novocastra; cat\# NCL-L-PSA-28A4; dilution 1:50) was applied at $37^{\circ} \mathrm{C}$ for 60 minutes. PSA staining was localized to the cytoplasm. Bound HOXB13 and PSA antibodies were visualized using the EnVision Kit (Dako, Glostrup, Denmark) according to the manufacturer's directions. Nuclear HOXB13 staining was evaluated according to the following scoring system: The staining intensity $(0,1+, 2+$, and $3+)$ and the fraction of positive tumor cells were recorded for each tissue spot. A final score was built from these two parameters according to the following established criteria. Negative: absence of staining; weak: staining intensity of $1+$ in $\leq 70 \%$ of tumor cells or staining intensity of $2+$ in $\leq$ $30 \%$ of tumor cells; moderate: staining intensity of $1+$ in $>70 \%$ of tumor cells or staining intensity of $2+$ in $>$ $30 \%$ but in $\leq 70 \%$ of tumor cells or staining intensity of $3+$ in $\leq 30 \%$ of tumor cells; strong: staining intensity of $2+$ in $>70 \%$ of tumor cells or staining intensity of $3+$ in $>30 \%$ of tumor cells. Cytoplasmic PSA staining intensity was estimated in a four-step scale including negative (no detectable staining), weak, moderate, and strong staining. 


\section{Statistics}

For statistical analysis, the JMP 9.0 software (SAS Institute Inc., NC, USA) was used. Contingency tables were calculated to study association between HOXB13 staining and clinico-pathological variables, and the Chisquare (Likelihood) test was used to find significant relationships. Kaplan Meier curves were generated for PSA recurrence free survival. The log-Rank test was applied to test the significance of differences between stratified survival functions. Cox proportional hazards regression analysis was performed to test the statistical independence and significance between pathological, molecular, and clinical variables.

\section{ACKNOWLEDGMENTS}

We thank Julia Schumann, Sünje Seekamp, and Inge Brandt for excellent technical assistance.

\section{Abbreviations}

AJCC: American joint committee on cancer; AKT: protein kinase B; AR: androgen receptor; CCND1: cyclin D1; CHD1: chromodomain-helicase DNA binding protein 1; cT: clinical tumor stage; CRISP3: cysteine-rich secretory protein 3; ERG: V-Ets avian erythroblastosis virus E26 oncogene homolog; FISH: fluorescence in situ hybridization; FOXP1: forkhead box protein 1; HOXB13: homeobox protein B13; IHC: immunohistochemistry; Ki67LI: Ki67 labeling index; MAP3K7: mitogen-activated protein kinase 7; mTOR: mammalian target of rapamycin, PSA: prostate-specific antigen; PTEN: phosphatase and tensin homolog; pT: pathological tumor stage, $\mathrm{pN}$ : pathological lymph node status; TMA: tissue micro array; TMPRSS2; transmembrane protease serine 2.

\section{REFERENCES}

1. Siegel R, Naishadham D, Jemal A. Cancer statistics, 2013. CA Cancer J Clin. 2013; 63:11-30.

2. Hombria JC, Lovegrove B. Beyond homeosis-HOX function in morphogenesis and organogenesis. Differentiation. 2003; 71:461-476.

3. Hueber SD, Lohmann I. Shaping segments: Hox gene function in the genomic age. Bioessays. 2008; 30:965-979.

4. Norris JD, Chang CY, Wittmann BM, Kunder RS, Cui H, Fan D, Joseph JD, McDonnell DP. The homeodomain protein HOXB13 regulates the cellular response to androgens. Mol Cell. 2009; 36:405-416.

5. Schroeck FR, Zuhlke KA, Siddiqui J, Siddiqui R, Cooney KA, Wei JT. Testing for the recurrent HOXB13 G84E germline mutation in men with clinical indications for prostate biopsy. J Urol. 2013; 189:849-853.
6. Stott-Miller M, Karyadi DM, Smith T, Kwon EM, Kolb S, Stanford JL, Ostrander EA. HOXB13 mutations in a population-based, case-control study of prostate cancer. Prostate. 2013; 73:634-641.

7. Xu J, Lange EM, Lu L, Zheng SL, Wang Z, Thibodeau SN, Cannon-Albright LA, Teerlink CC, Camp NJ, Johnson AM, Zuhlke KA, Stanford JL, Ostrander EA, Wiley KE, Isaacs $\mathrm{SD}$, Walsh PC, et al. HOXB13 is a susceptibility gene for prostate cancer: results from the International Consortium for Prostate Cancer Genetics (ICPCG). Hum Genet. 2013; 132:5-14.

8. Ewing CM, Ray AM, Lange EM, Zuhlke KA, Robbins CM, Tembe WD, Wiley KE, Isaacs SD, Johng D, Wang Y, Bizon C, Yan G, Gielzak M, Partin AW, Shanmugam V, Izatt $\mathrm{T}$, et al. Germline mutations in HOXB13 and prostatecancer risk. N Engl J Med. 2012; 366:141-149.

9. Lynch HT, Shaw TG. Familial prostate cancer and HOXB13 founder mutations: geographic and racial/ethnic variations. Hum Genet. 2013; 132:1-4.

10. Akbari MR, Anderson LN, Buchanan DD, Clendenning M, Jenkins MA, Win AK, Hopper JL, Giles GG, Nam R, Narod S, Gallinger S, Cleary SP. Germline HOXB13 p.Gly84Glu mutation and risk of colorectal cancer. Cancer Epidemiol. 2013; 37:424-427.

11. Witte JS, Mefford J, Plummer SJ, Liu J, Cheng I, Klein EA, Rybicki BA, Casey G. HOXB13 mutation and prostate cancer: studies of siblings and aggressive disease. Cancer Epidemiol Biomarkers Prev. 2013; 22:675-680.

12. Kim YR, Oh KJ, Park RY, Xuan NT, Kang TW, Kwon DD, Choi C, Kim MS, Nam KI, Ahn KY, Jung C. HOXB13 promotes androgen independent growth of $\mathrm{LNCaP}$ prostate cancer cells by the activation of E2F signaling. Mol Cancer. 2010; 9:124.

13. Varinot J, Cussenot O, Roupret M, Conort P, Bitker MO, Chartier-Kastler E, Cheng L, Comperat E. HOXB13 is a sensitive and specific marker of prostate cells, useful in distinguishing between carcinomas of prostatic and urothelial origin. Virchows Arch. 2013; 463:803-809.

14. Hamid SM, Cicek S, Karamil S, Ozturk MB, DebelecButuner B, Erbaykent-Tepedelen B, Varisli L, GonenKorkmaz C, Yorukoglu K, Korkmaz KS. HOXB13 contributes to $\mathrm{G} 1 / \mathrm{S}$ and $\mathrm{G} 2 / \mathrm{M}$ checkpoint controls in prostate. Mol Cell Endocrinol. 2014; 383:38-47.

15. Jeong TO, Oh KJ, Xuan Nguyen NT, Kim YR, Kim MS, Lee SD, Ryu SB, Jung C. Evaluation of HOXB13 as a molecular marker of recurrent prostate cancer. Mol Med Rep. 2012; 5:901-904.

16. Ahyai SA, Graefen M, Steuber T, Haese A, Schlomm T, Walz J, Kollermann J, Briganti A, Zacharias M, Friedrich MG, Karakiewicz PI, Montorsi F, Huland H, Chun FK. Contemporary prostate cancer prevalence among T1c biopsy-referred men with a prostate-specific antigen level $<$ or $=4.0$ ng per milliliter. Eur Urol. 2008; 53:750-757. 
17. Kononen J, Bubendorf L, Kallioniemi A, Barlund M, Schraml P, Leighton S, Torhorst J, Mihatsch MJ, Sauter G, Kallioniemi OP. Tissue microarrays for high-throughput molecular profiling of tumor specimens. Nat Med. 1998; 4:844-847.

18. Weischenfeldt J, Simon R, Feuerbach L, Schlangen K, Weichenhan D, Minner S, Wuttig D, Warnatz HJ, Stehr H, Rausch T, Jäger N, Gu L, Bogatyrova O, Stütz A, Claus R, Eils J, et al. Integrative genomic analyses reveal androgendriven somatic alteration landscape in early-onset prostate cancer. Cancer Cell. 2013; 23:159-170.

19. Minner S, Enodien M, Sirma H, Luebke AM, Krohn A, Mayer PS, Simon R, Tennstedt P, Muller J, Scholz L, Brase JC, Liu AY, Schluter H, Pantel K, Schumacher U, Bokemeyer $\mathrm{C}$, et al. ERG status is unrelated to PSA recurrence in radically operated prostate cancer in the absence of antihormonal therapy. Clin Cancer Res. 2011; 17:5878-5888.

20. Burkhardt L, Fuchs S, Krohn A, Masser S, Mader M, Kluth M, Bachmann F, Huland H, Steuber T, Graefen M, Schlomm T, Minner S, Sauter G, Sirma H, Simon R. CHD1 is a 5 q21 tumor suppressor required for ERG rearrangement in prostate cancer. Cancer Res. 2013; 73:2795-2805.

21. Kluth M, Hesse J, Heinl A, Krohn A, Steurer S, Sirma H, Simon R, Mayer PS, Schumacher U, Grupp K, Izbicki JR, Pantel K, Dikomey E, Korbel JO, Plass C, Sauter G, et al. Genomic deletion of MAP3K7 at 6q12-22 is associated with early PSA recurrence in prostate cancer and absence of TMPRSS2:ERG fusions. Mod Pathol. 2013; 26:975-983.

22. Krohn A, Diedler T, Burkhardt L, Mayer PS, De Silva C, Meyer-Kornblum M, Kotschau D, Tennstedt P, Huang J, Gerh T, Graefen M, et al. Genomic deletion of PTEN is associated with tumor progression and early PSA recurrence in ERG fusion-positive and fusion-negative prostate cancer. Am J Pathol. 2012; 181:401-412.

23. Krohn A, Seidel A, Burkhardt L, Bachmann F, Mader M, Grupp K, Eichenauer T, Becker A, Adam M, Graefen M, Huland H, Kurtz S, Steurer S, Tsourlakis MC, Minner S, Michl U, et al. Recurrent deletion of 3p13 targets multiple tumour suppressor genes and defines a distinct subgroup of aggressive ERG fusion-positive prostate cancers. J Pathol. 2013; 231:130-141.

24. Minner S, Jessen B, Stiedenroth L, Burandt E, Kollermann J, Mirlacher M, Erbersdobler A, Eichelberg C, Fisch M, Brummendorf TH, Bokemeyer C, Simon R, Steuber T, Graefen M, Huland H, Sauter G, et al. Low level HER2 overexpression is associated with rapid tumor cell proliferation and poor prognosis in prostate cancer. Clin Cancer Res. 2010; 16:1553-1560.

25. Kim SD, Park RY, Kim YR, Kim IJ, Kang TW, Nam KI, Ahn KY, Bae CS, Kim BY, Park SS, Jung C. HOXB13 is co-localized with androgen receptor to suppress androgenstimulated prostate-specific antigen expression. Anat Cell Biol. 2010; 43:284-293.

26. Epstein JI, Feng Z, Trock BJ, Pierorazio PM. Upgrading and downgrading of prostate cancer from biopsy to radical prostatectomy: incidence and predictive factors using the modified Gleason grading system and factoring in tertiary grades. Eur Urol. 2012; 61:1019-1024.

27. Schlomm T, Iwers L, Kirstein P, Jessen B, Kollermann J, Minner S, Passow-Drolet A, Mirlacher M, MildeLangosch K, Graefen M, Haese A, Steuber T, Simon R, Huland H, Sauter G, Erbersdobler A. Clinical significance of p53 alterations in surgically treated prostate cancers. Mod Pathol. 2008; 21:1371-1379.

28. Jung C, Kim RS, Zhang HJ, Lee SJ, Jeng MH. HOXB13 induces growth suppression of prostate cancer cells as a repressor of hormone-activated androgen receptor signaling. Cancer Res. 2004; 64:9185-9192.

29. Lee MS, Igawa T, Yuan TC, Zhang XQ, Lin FF, Lin MF. ErbB-2 signaling is involved in regulating PSA secretion in androgen-independent human prostate cancer LNCaP C-81 cells. Oncogene. 2003; 22:781-796.

30. Tomlins SA, Rhodes DR, Perner S, Dhanasekaran SM, Mehra R, Sun XW, Varambally S, Cao X, Tchinda J, Kuefer R, Lee C, Montie JE, Shah RB, Pienta KJ, Rubin MA, Chinnaiyan AM. Recurrent fusion of TMPRSS2 and ETS transcription factor genes in prostate cancer. Science. 2005; 310:644-648.

31. Jhavar S, Reid A, Clark J, Kote-Jarai Z, Christmas T, Thompson A, Woodhouse C, Ogden C, Fisher C, Corbishley C, De-Bono J, Eeles R, Brewer D, Cooper C. Detection of TMPRSS2-ERG translocations in human prostate cancer by expression profiling using GeneChip Human Exon 1.0 ST arrays. J Mol Diagn. 2008; 10:50-57.

32. Gupta S, Iljin K, Sara H, Mpindi JP, Mirtti T, Vainio P, Rantala J, Alanen K, Nees M, Kallioniemi O. FZD4 as a mediator of ERG oncogene-induced WNT signaling and epithelial-to-mesenchymal transition in human prostate cancer cells. Cancer Res. 2010; 70:6735-6745.

33. Brase JC, Johannes M, Mannsperger H, Falth M, Metzger J, Kacprzyk LA, Andrasiuk T, Gade S, Meister M, Sirma H, Sauter G, Simon R, Schlomm T, Beissbarth T, Korf U, Kuner R, et al. TMPRSS2-ERG -specific transcriptional modulation is associated with prostate cancer biomarkers and TGF-beta signaling. BMC Cancer. 2011; 11:507.

34. Iljin $\mathrm{K}$, Wolf $\mathrm{M}$, Edgren $\mathrm{H}$, Gupta $\mathrm{S}$, Kilpinen $\mathrm{S}$, Skotheim RI, Peltola M, Smit F, Verhaegh G, Schalken J, Nees M, Kallioniemi O. TMPRSS2 fusions with oncogenic ETS factors in prostate cancer involve unbalanced genomic rearrangements and are associated with HDAC1 and epigenetic reprogramming. Cancer Res. 2006; 66:10242-10246.

35. Mani RS, Tomlins SA, Callahan K, Ghosh A, Nyati MK, Varambally S, Palanisamy N, Chinnaiyan AM. Induced chromosomal proximity and gene fusions in prostate cancer. Science. 2009; 326:1230.

36. Mao X, Boyd LK, Yanez-Munoz RJ, Chaplin $T$, Xue L, Lin D, Shan L, Berney DM, Young BD, Lu YJ. Chromosome rearrangement associated inactivation of tumour suppressor genes in prostate cancer. Am J Cancer Res. 2011; 1:604-617. 
37. Ellis SD, Blackard B, Carpenter WR, Mishel M, Chen RC, Godley PA, Mohler JL, Bensen JT. Receipt of National Comprehensive Cancer Network guideline-concordant prostate cancer care among African American and Caucasian American men in North Carolina. Cancer. 2013; 119:2282-2290.

38. Smith SC, Palanisamy N, Zuhlke KA, Johnson AM, Siddiqui J, Chinnaiyan AM, Kunju LP, Cooney KA, Tomlins SA. HOXB13 G84E-related familial prostate cancers: a clinical, histologic, and molecular survey. Am J Surg Pathol. 2014; 38:615-626.

39. Berger MF, Lawrence MS, Demichelis F, Drier Y, Cibulskis K, Sivachenko AY, Sboner A, Esgueva R, Pflueger D, Sougnez C, Onofrio R, Carter SL, Park K, Habegger L, Ambrogio L, Fennell T, et al. The genomic complexity of primary human prostate cancer. Nature. 2011; 470:214-220.

40. Lapointe J, Kim YH, Miller MA, Li C, Kaygusuz G, van de Rijn M, Huntsman DG, Brooks JD, Pollack JR. A variant TMPRSS2 isoform and ERG fusion product in prostate cancer with implications for molecular diagnosis. Mod Pathol. 2007; 20:467-473.

41. Taylor BS, Schultz N, Hieronymus H, Gopalan A, Xiao Y, Carver BS, Arora VK, Kaushik P, Cerami E, Reva B, Antipin Y, Mitsiades N, Landers T, Dolgalev I, Major JE, Wilson $\mathrm{M}$, et al. Integrative genomic profiling of human prostate cancer. Cancer Cell. 2010; 18:11-22.

42. Grupp K, Kohl S, Sirma H, Simon R, Steurer S, Becker A, Adam M, Izbicki J, Sauter G, Minner S, Schlomm T, Tsourlakis MC. Cysteine-rich secretory protein 3 overexpression is linked to a subset of PTEN-deleted ERG fusionpositive prostate cancers with early biochemical recurrence. Mod Pathol. 2013; 26:733-742.

43. Grupp K, Diebel F, Sirma H, Simon R, Breitmeyer K, Steurer S, Hube-Magg C, Prien K, Pham T, Weigand P, Michl U, Heinzer H, Kluth M, Minner S, Tsourlakis MC, Izbicki JR, et al. SPINK1 expression is tightly linked to 6q15and 5q21-deleted ERG-fusion negative prostate cancers but unrelated to PSA recurrence. Prostate. 2013; 73:1690-1698.

44. Shah N, Jin K, Cruz LA, Park S, Sadik H, Cho S, Goswami CP, Nakshatri H, Gupta R, Chang HY, Zhang Z, Cimino-Mathews A, Cope L, Umbricht C, Sukumar S. HOXB13 mediates tamoxifen resistance and invasiveness in human breast cancer by suppressing ERalpha and inducing IL-6 expression. Cancer Res. 2013; 73:5449-5458.

45. Schroder FH, Hugosson J, Roobol MJ, Tammela TL, Ciatto S, Nelen V, Kwiatkowski M, Lujan M, Lilja H, Zappa M, Denis LJ, Recker F, Paez A, Maattanen L, Bangma CH, Aus G, et al. Prostate-cancer mortality at 11 years of follow-up. N Engl J Med. 2012; 366:981-990.

46. Stattin P, Carlsson S, Holmstrom B, Vickers A, Hugosson J, Lilja H, Jonsson H. Prostate cancer mortality in areas with high and low prostate cancer incidence. J Natl Cancer Inst. 2014; 106:dju007.
47. Schlomm T, Erbersdobler A, Mirlacher M, Sauter G. Molecular staging of prostate cancer in the year 2007. World J Urol. 2007; 25:19-30.

48. Rye MB, Bertilsson H, Drablos F, Angelsen A, Bathen TF, Tessem MB. Gene signatures ESC, MYC and ERG-fusion are early markers of a potentially dangerous subtype of prostate cancer. BMC Med Genomics. 2014; 7:50.

49. Chen X, Xu S, McClelland M, Rahmatpanah F, Sawyers A, Jia Z, Mercola D. An accurate prostate cancer prognosticator using a seven-gene signature plus Gleason score and taking cell type heterogeneity into account. PLoS One. 2012; 7:e45178.

50. Cuzick J, Dowsett M, Pineda S, Wale C, Salter J, Quinn E, Zabaglo L, Mallon E, Green AR, Ellis IO, Howell A, Buzdar AU, Forbes JF. Prognostic value of a combined estrogen receptor, progesterone receptor, $\mathrm{Ki}-67$, and human epidermal growth factor receptor 2 immunohistochemical score and comparison with the Genomic Health recurrence score in early breast cancer. J Clin Oncol. 2011; 29:4273-4278.

51. Knezevic D, Goddard AD, Natraj N, Cherbavaz DB, Clark-Langone KM, Snable J, Watson D, Falzarano SM, Magi-Galluzzi C, Klein EA, Quale C. Analytical validation of the Oncotype DX prostate cancer assay - a clinical RT-PCR assay optimized for prostate needle biopsies. BMC Genomics. 2013; 14:690.

52. Ross AE, Feng FY, Ghadessi M, Erho N, Crisan A, Buerki C, Sundi D, Mitra AP, Vergara IA, Thompson DJ, Triche TJ, Davicioni E, Bergstralh EJ, Jenkins RB, Karnes RJ, Schaeffer EM. A genomic classifier predicting metastatic disease progression in men with biochemical recurrence after prostatectomy. Prostate Cancer Prostatic Dis. 2014; 17:64-69.

53. Grupp K, Habermann M, Sirma H, Simon R, Steurer S, Hube-Magg C, Prien K, Burkhardt L, Jedrzejewska K, Salomon G, Heinzer H, Wilczak W, Kluth M, Izbicki JR, Sauter G, Minner S, et al. High nuclear karyopherin alpha 2 expression is a strong and independent predictor of biochemical recurrence in prostate cancer patients treated by radical prostatectomy. Mod Pathol. 2014; 27:96-106.

54. Tsourlakis MC, Schoop M, Plass C, Huland H, Graefen M, Steuber T, Schlomm T, Simon R, Sauter G, Sirma H, Minner S. Overexpression of the chromatin remodeler death-domain-associated protein in prostate cancer is an independent predictor of early prostate-specific antigen recurrence. Hum Pathol. 2013; 44:1789-1796.

55. Grupp K, Sanader S, Sirma H, Simon R, Koop C, Prien K, Hube-Magg C, Salomon G, Graefen M, Heinzer H, Minner S, Izbicki JR, Sauter G, Schlomm T, Tsourlakis MC. High lysophosphatidylcholine acyltransferase 1 expression independently predicts high risk for biochemical recurrence in prostate cancers. Mol Oncol. 2013; 7:1001-1011. 